\title{
Energy savings in transportation systems by weight reduction of their components
}

\author{
- Research and development of non-combustible magnesium alloys - \\ Michiru Sakamoto ${ }^{1 *}$ and Hidetoshi Ueno ${ }^{2}$
}

[Translation from Synthesiology, Vol.2, No.2, p.127-136 (2009)]

\begin{abstract}
Technological innovation bringing direct energy savings and reductions in carbon-dioxide emissions has been cited as an urgent issue in the field of transportation machinery. To cope with this issue, demand has been growing for structural materials that are lightweight yet offer high functionality because weight reduction of machinery can be immediately beneficial. A new non-combustible magnesium alloy with drastically improved areas of application is sought in which flammability is suppressed - - the worst weakness of magnesium alloys. Developing this new alloy as a basic component for reducing environmental load will contribute greatly to technological innovation for weight reduction in transportation machinery. This paper examines one methodology for industrialization of a new material through the resolution of the various technical issues related to practical application of non-combustible magnesium alloys.
\end{abstract}

Keywords : Non-combustible magnesium alloy, $\mathrm{SF}_{6}$ gas-free process, basic material, lightweight structural materials, research network

\section{Research objective and outcome}

Energy saving in the transportation field, which consumes a large part of our energy and is expected to grow dramatically in the future, is an urgent issue that must be solved globally. One of the most direct and effective measures is to reduce the weight of the transportation machinery. The current transportation machineries are made of core materials including steel, iron, and aluminum, but a lighter weight material is desired as a new core material. Magnesium is one of the candidates that fulfill this objective, and it is recently receiving attention due to the social demand and concern for environment-friendly recycling technology. It is a remarkably abundant resource, is available throughout the world, can be easily recovered as metal material, is safe without environmental toxicity, and therefore has high potential to become a recyclable core material like iron, steel, and aluminum. However, it never became a core material due to various technological issues. If we are able to quantify the properties of magnesium from an industrial viewpoint and nurture it as a core material, it can certainly contribute to a truly sustainable society in terms of optimization of resource and energy use.

Specifically, practical application of magnesium will allow weight reduction in almost all moving things. High efficiency can be realized through weight reduction of transportation machineries such as automobiles, railroad vehicles, and aircrafts, as well as machine components and robots. The initial goal will be to save energy by using magnesium in railroad vehicle components, since railroad is a mass transportation system with excellent energy efficiency. Through future developments in mass production technology this will be followed by wider application to machine structural materials such as in automobiles. This will help establish magnesium as a core material that is in itself environmentally sustainable, and will contribute in saving energy of transportation machineries.

\section{Greatest problem with magnesium}

The greatest and most serious problem with magnesium is that it burns in the atmosphere. Despite the fact that magnesium was already put to practical use as a structural material for aircrafts before the World War, this combustible property was a major psychological barrier for civilian use. In terms of manufacturing technology, melting and casting processes of magnesium are special due to its ignition and combustion properties, and it was difficult to apply the general metal material techniques that have been developed so far. The research for noncombustible magnesium concentrated on establishing a low-cost process acceptable to industry, and centered mainly on the development of a process that can be used in ordinary atmosphere by making the magnesium less combustible. Particularly, the process that does not use sulfur hexafluoride $\left(\mathrm{SF}_{6}\right)$ gas, which is necessary as fireproof gas in the melting process, is an important technology that will determine the future direction of this industry, since $\mathrm{SF}_{6}$ is a global greenhouse gas that places a burden on the environment. With these possible developments, the manufacturing technology for magnesium can be converted from a special technology into a common one. We aim to

1. Materials Research Institute for Sustainable Development, AIST Anagahora 2266-98, Shimo-shidami, Moriyama-ku, Nagoya 463- 8560, Japan *E-mail: michiru-sakamoto@aist.go.jp, 2. Materials Research Institute for Sustainable Development, AIST Shuku-machi 807-1, Tosu 841-0052, Japan

Received original manuscript January 23, 2009, Revisions received March 30, 2009, Accepted March 30, 2009 
establish a highly efficient mass production process that is also safe and environment-friendly, by turning something considered to be a special material into a core material that can be used readily by everyone.

The manufacturing technology for noncombustible magnesium is not only a blessing for the manufacturer in terms of safety at the plant and decreased cost of production (special facilities are not needed), but also satisfies the user's demand for safety. In addition to psychological fear for magnesium ignition, the issue of safety in accidents and fires was an important point that was often ignored.

\subsection{Discovery of noncombustibility by addition of calcium and the mechanism of noncombustibility}

The discovery of noncombustibility was like finding a bargain. In the development of lightweight metal matrix composites in which various ceramic fine particles are dispersed in aluminum, to directly mix and disperse the ceramic fine particles into the molten aluminum, it is important to improve the wettability of the molten metal and the particle surface and to optimally control the viscosity of molten aluminum. In the process of investigating the effect of adding various elements to the property of molten metal, it was found that calcium was effective in controlling the viscosity of the molten metal, and the low-cost manufacturing process for fine particle dispersed aluminum alloy composite was developed. The study of noncombustible magnesium alloys started from the accidental discovery of noncombustibility in the atmosphere, or the dramatic change in the property after adding calcium to the molten magnesium in the process of applying this technology to molten magnesium for further weight reduction. Figure 1 shows the ignition temperature in the atmosphere of a major noncombustible magnesium alloy AZX912 (A=A1, Z=Zn, $\mathrm{X}=\mathrm{Ca}$, number is $\mathrm{wt} \%)$. As apparent in this figure, addition of calcium increases the ignition temperature by over 200 ${ }^{\circ} \mathrm{C}$. Melting in the atmosphere becomes possible when the ignition temperature rises to this level.

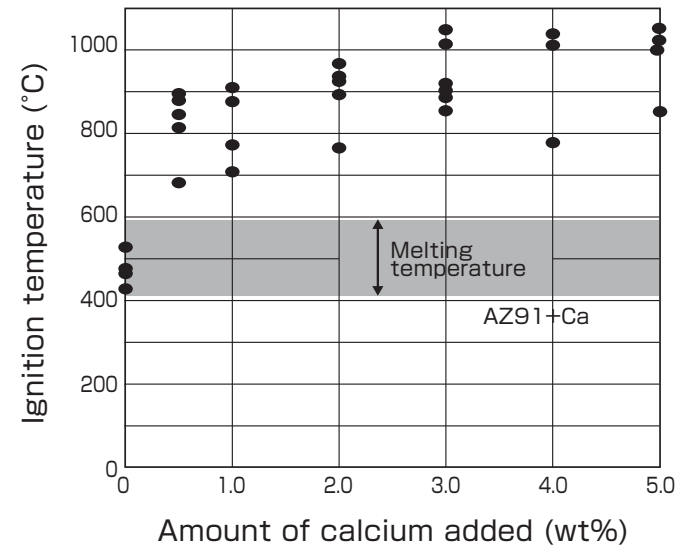

Fig. 1 Ignition temperature of noncombustible magnesium alloy (AZX912).
On the other hand, just as in ignition property, the state of oxides formed on the surface of molten magnesium differs significantly according to whether it contains calcium or not. In case of pure magnesium, the surface oxide of the sample, which was molten in inert atmosphere, immediately exposed to the atmosphere, and cooled rapidly before it ignited, had grown extremely thick even when the time exposed to the atmosphere in the molten condition was only a few seconds. The structure was porous composed of fine particles, and it could be inferred that the oxide did not provide a protective film for the surface. This is shown in the SEM photograph of the oxide surface in Fig. 2. In the figure, (a) is the overall structure at low magnification, and (b) is the enlarged structure at high magnification. The structure of the oxide can be seen from how it is formed. At melting point temperature, with pure magnesium the volume ratio of the produced oxide (Pilling-Bedworth ratio) is much smaller than 1 , and the produced oxide will not function as a protective film that completely covers the surface of the molten metal. This is thought to be the reason why the oxidized film formed on the alloy that does not contain calcium has a porous structure.

In contrast, the surface of the oxide of calcium-containing alloys is shown in the SEM photograph in Fig. 3. In this figure, (a) is the overall structure at low magnification, and (b) is the enlarged structure at high magnification. In the calcium-containing alloy, the film formed does not grow thick even if the surface is sufficiently oxidized by exposing to the atmosphere for $1 \mathrm{hr}$, and the surface structure is extremely dense. The oxidized film formed on the magnesium containing calcium presents a completely different state compared to the magnesium not containing calcium. This shows that when the alloy with calcium is in a molten state, a dense oxidized film forms on the surface, and this functions as an extremely effective protective film against oxidation.

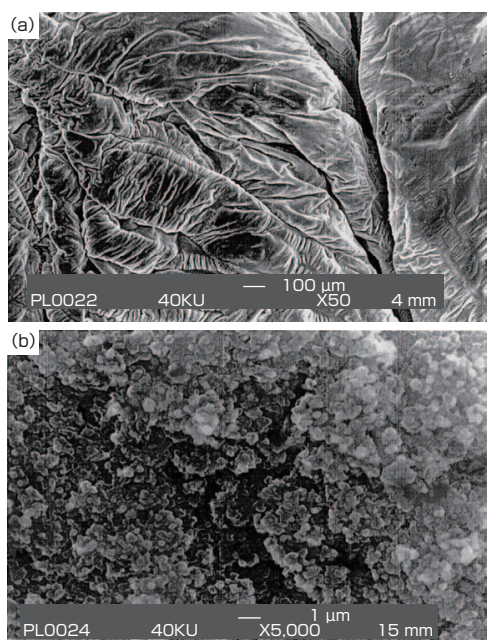

Fig. 2 Surface structure of oxide film in pure magnesium. 
The significant difference between the surface structures of pure magnesium and magnesium-calcium alloys shows that there are differences in the constituent phase and formation mechanism of the oxidized film. Studying the oxidized film carefully, it was clarified that the outermost layer of the surface oxides of calcium-containing alloys was mainly composed of oxidized calcium ${ }^{[1]}$. Since this oxide has a dense structure, it acts as an effective barrier against oxygen supply from the atmosphere and against evaporation of magnesium from the molten surface, and the ignition temperature is thought to increase due to this protective action.

Although why such a dense oxide film forms only on calcium-containing alloys is a very important and interesting issue, not much is known about the formation mechanism. Calcium is more active than magnesium, and a dense surface oxide film is not formed in calcium alone, as in magnesium alone (or a magnesium alloy without calcium). What is clear is that the coexistence of magnesium and calcium is significant. When oxidation occurs when calcium and magnesium are coexisting, various interactions occur. Since calcium is one of the few elements that can be expected to reduce magnesium oxides at temperature range near the melting point, the formation of the outermost oxidized film layer composed of calcium oxide is probably a complex process that involves the reduction of magnesium oxide by calcium and production of calcium oxide, in addition to the preferential oxidation of calcium over magnesium.

After the discovery of the effect of calcium, the search for a similar effect among various elements was futile, and no additive element that showed dramatic ignition suppression like calcium was discovered. To the present, we found no element that enhanced noncombustibility as much as calcium. It is thought that this is an appropriate conclusion, since, considering the above mechanism, the only element with lower free energy to form oxide than magnesium is

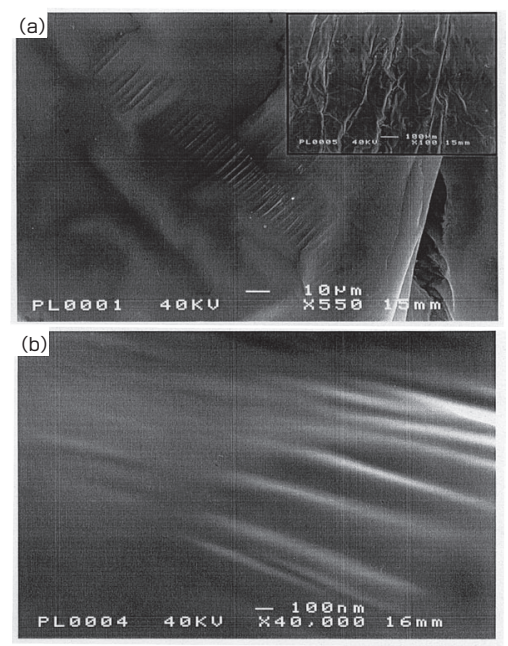

Fig. 3 Surface structure of oxide film in $\mathrm{Mg}-5 \mathrm{Ca}$ binary alloy. calcium.

\section{Solution of individual elemental technology issues}

For practical application, it is necessary to appropriately set the individual elemental technology issues and solve them one at a time. However, this is easier said than done. If issues are dealt with as they arise, a long time will be required to reach the goal. A clear scenario is necessary to send out a new material to the world. In the development of noncombustible magnesium, (1) following the discovery of a new raw material described above, (2) the development of refining technology to raise the raw material to material, (3) the technology for fabricating members (forming and processing technology), (4) the reliability assessment, and (5) a technological breakthrough in the product realization phase were necessary.

Through the mechanism described in the previous section, calcium-containing alloys can be melted and cast in the atmosphere safely, and the manufacturing process can be done safely and simply using the magnesium-based alloy. To be simple is important from the industrial perspective. The most important point here is to be conscious that the original motivation for employing magnesium as a core material is to realize a low environment load society that may become possible if magnesium is used. Therefore, this development will be meaningless unless all elemental technologies follow the guiding principle. The outline is described as follows.

\subsection{Clean molten metal refining technology}

In noncombustible alloys, active metal calcium is added to active magnesium, and, inclusions such as oxides that are produced in the smelting process ${ }^{\text {Term } 1}$ mix into the molten metal in larger amounts compared to other alloys, and this may affect strength and corrosion resistance. Since the specific gravity of the inclusions is close to that of the molten metal, it is difficult to separate them by precipitation or floating, and therefore, complete separation and removal are difficult. Normally, they are removed using flux such as chlorides or fluorides of magnesium or calcium. However, the corrosive resistance is compromised if the flux remains even in small quantity, and the material yield may be decreased if attempt is made to avoid this problem. Also, there is the problem of industrial waste composed of chlorides and fluorides. Even if an atmospheric melting process that does not use fireproof gas or flux is developed, the value of this technology is greatly diminished if flux or other materials are used in the refining process. Our condition for survival was to develop an environmentally clean, simple, and yet effective method.

We focused on the fact that in addition to the prevention of oxidation by the dense oxide film formed on the surface of 
the molten noncombustible alloy, the high vapor pressure of the molten magnesium appeared to be held extremely low. This, in other words, was the development of a refining technology by a reduced pressure method, and it was a breakthrough for converting the noncombustible magnesium alloy into a practical material. This method is characterized by being extremely simple so it can be executed easily, and therefore can be implemented in large-scale production facilities.

The reduced pressure method is a simple method for removing the inclusions by floating and separating them on the surface of the molten alloy, by maintaining the molten state under decompression. Since various gases are dissolved in the molten metal, the inclusion floats to the surface of the molten metal by attaching to the gas bubbles generated by reduced pressure. In ordinary magnesium alloys, since the vapor pressure is high, the pressure cannot be reduced. In noncombustible magnesium alloys, the metal vapor pressure becomes extremely low in appearance due to the oxide film formed over the molten metal surface, and therefore, reduced pressure refining can be applied as in aluminum, iron and steel. The target pressure can be reached sufficiently by the evacuation capacity of an ordinary mechanical pump, and the retention time is several seconds to several minutes depending on the quantity of the molten metal. Therefore, it can be applied readily to a large melting furnace. Figure 4 shows the melting furnace with $100 \mathrm{~kg}$ capacity for noncombustible magnesium alloys at AIST. It is equipped with the reduced pressure refining mechanism. In the conventional flux method, the working environment deteriorates due to steam originating from flux, but in this method, the working environment remains safe and clean, and the integrity of the material will not be lost since no flux will remain in the molten metal. This technology, at present, has been transferred to four companies and the development of a mass production process is in progress. This series of smelting process is mainly atmospheric melting. It is

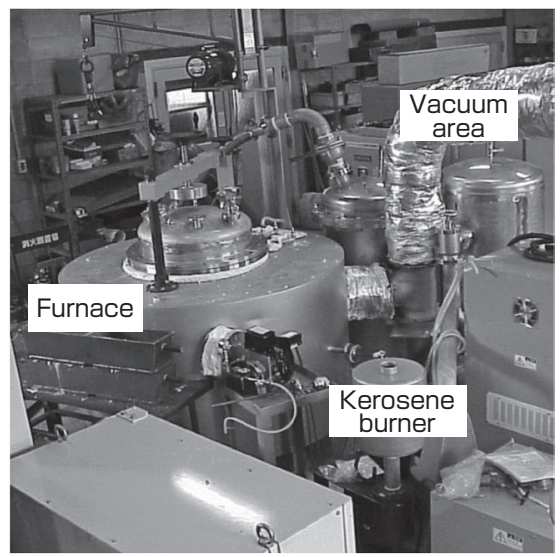

Fig. 4 Smelting furnace for noncombustible magnesium alloy equipped with reduced pressure refinement mechanism (capacity100 kg). basically an atmospheric process where in the final step, refining is done by placing a lid and reducing pressure to remove the inclusions. It leads directly to cost reduction of the casting process, and has been put to actual practice. However in reality, many know-hows are required to cast noncombustible alloys, as will be described later.

\subsection{Plastic forming process}

The second issue pertains to the plastic forming process. Compared to aluminum, iron and steel, the formability of magnesium in the cold process ${ }^{\text {Term } 2}$ is poor, and there is a great risk when a user introduces this process for the first time. This raises the manufacturing cost of magnesium and becomes a realistic barrier in industry. While alloys of iron, steel, and aluminum have cubic crystal structure with small anisotropy, magnesium is a hexagonal crystal structure with large anisotropy, and therefore does not show rich formability in the cold process, and also has a basic problem in the plastic forming process. The problem is more serious in noncombustible alloys. Since magnesium alloys must contain aluminum to increase its strength and corrosion resistance, high melting point aluminum-calcium intermetallic compound is formed due to the calcium added for noncombustibility, and this becomes a primary crystal that crystallizes as a network into the grain boundary, decreases the flow of the molten metal, and negatively affects the mechanical properties, particularly the ductibility. This is shown in Fig. 5a. Since the aluminum-calcium intermetallic compound has extremely small solid solubility into the metal matrix, it is not easy to control such solidification structure by heat treatment.

On the other hand, the situation is different when plastic forming is considered. Even with a noncombustible alloy of poor plastic formability, good formability can be achieved by applying the extrusion process that is a hydrostatic
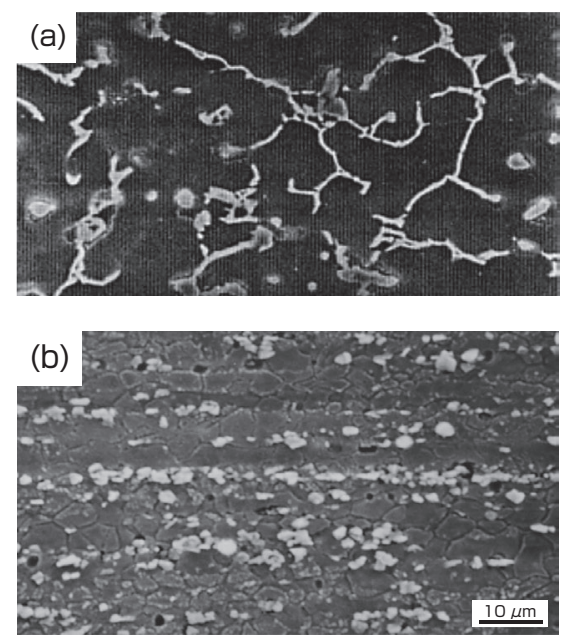

Fig. 5 Structure of noncombustible magnesium alloy (AMX602).

a: Solidified structure, b: Structure after extrusion. 
processing method during the hot process ${ }^{\text {Term } 2}$. The networkform aluminum-calcium intermetallic compound in the grain boundary is crushed finely in the direction of extrusion. The crystal grain of the metal matrix becomes smaller by the recrystallization effect, and the overall structure becomes extremely fine (Fig. 5b). The strength and elongation properties increase significantly. Figure 6 shows the mechanical property of the AMX602 alloy. In case of the extruded materials, the room temperature elongation improved to the level of over $20 \%$ in materials that underwent T4 treatment ${ }^{\text {Term } 3}$ after hot extrusion. This shows that a material with good balance of strength and elongation can be obtained if the plastic forming of noncombustible alloys is done optimally.

Important plastic forming technology includes forging and rolling. Along with product development by hot extrusion, it is necessary to develop a manufacturing technology for forging and rolling using the extruded material as a starting material. Also, the research is in progress for direct casting technique from low cost continuously casted material where the solidification structure is finely controlled. For plate material, composition and structure with excellent cold forming property is being discovered as a result of basic research, and it is entering the development phase for lowcost mass-production technology. Also, further basic research is necessary to compensate for the lack of alloy types for magnesium alloys, particularly for high strength and heat resistant materials.

To realize this alloy as a structural material, reliability assessment is important. Figure 7 is an example of the endurance strength assessment by rotary bending of extruded noncombustible alloy AMX602. The characteristic of this material is its clear endurance limit. It is also known to have a lower notch sensitivity compared to aluminum alloys ${ }^{[2]-[4]}$, and can be used readily as a structural material. However, all fractures start at the inclusion initiation point ${ }^{\text {Term } 4}$, and a clean manufacturing technology of high quality material is extremely important ${ }^{[2]}$.

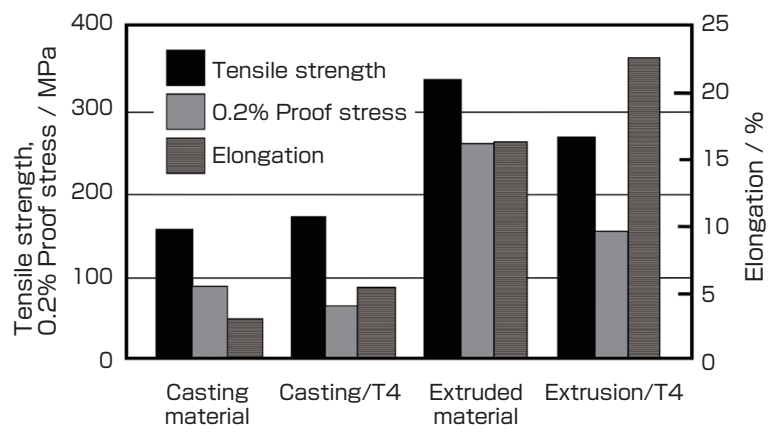

Fig. 6 Mechanical property of noncombustible magnesium alloy (AMX602).

\subsection{Recycling technology}

As a guideline of material selection for the user, high recyclability is recently becoming important. Recyclability is an important property linked directly to manufacturing cost. As part of recycling research, an in-house recycling technology during smelting is being developed by the foundries, and the current refining level is recycled material use of $50 \%$ or more. An example of mechanical pulverization in the atmosphere is shown in Fig. 8, as a case investigating the safety when used as an automobile component to be shredder treated later and the usability of the material after shredder treatment. The photograph shows the particle of sieve gauge of under $38 \mu \mathrm{m}$, and this indicates that mechanical pulverization can be accomplished safely. To study the use of such pulverized particles, the adsorption property of arsenic, boron, zinc, and chromium in wastewater were investigated, and magnesium hydroxides were demonstrated to be powerful adsorbents ${ }^{[5]-[7]}$.

\section{Industry-academia-government collaboration scheme for product realization}

To send out a new material into the world, a clear vision and a scenario for its realization are necessary, after carefully looking at the overall picture of the technology the new material may promote. The noncombustible magnesium alloy is not flammable, so it can be developed in the same manner as ordinary metal materials. However, since it is similar but different from the existing aluminum alloys, it is necessary to prepare the comprehensive technological data and processing systems as in other metal materials.

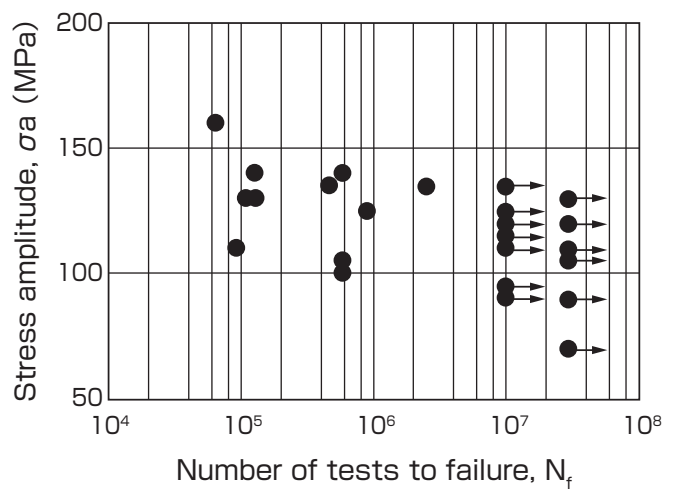

Fig. 7 Endurance strength assessment of noncombustible magnesium alloy (AMX602).

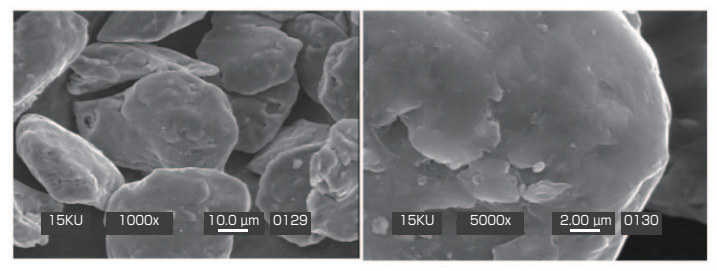

Fig. 8 Crushed particles of noncombustible magnesium alloy (AMX602) (sieve gauge $38 \mu \mathrm{m}$ ). 
Therefore, it was necessary to write the scenario from the perspective of what would be the individual technologies adapted to magnesium. Fortunately, we were able to establish a collaborative organization with a common objective, with several companies in different businesses that were interested in noncombustible magnesium and saw its unique potential. We were able to write and share the scenario of R\&D through this collaboration and were able to engage in development efficiently.

A material is a material only when it is used, and wideranging accumulation of technologies and experiences is necessary, just as it was with the conventional materials. If it is to be employed as a core material, further accumulation of integrated technology is needed, and normally, extremely long time is required if this process is left to a natural course of development. To accelerate the practical use of noncombustible magnesium, we made conscious effort to engage in $R \& D$ under one scenario, which is the realization of the material, while sharing an integrated and total vision with the members to develop individual elemental technologies. Through the activities in which the elemental technologies mutually influenced each other, we rapidly shifted the image of a novel material to an industrial material, and nurtured it as a core material. To accomplish this, we found that R\&D through wide-ranging collaborative network of institutions with varying characters, including companies, universities, and public research institutions was effective.

We engaged in R\&D with shared objective of application through the integration of technology, or the construction of an environment-friendly material system. For efficient research, a planar R\&D system was created through collaboration of research activities that differ in character, using industry as a vertical line and core technology as a horizontal line. For industry, the technical issues became clear by taking a vertical collaborative system with mutual feedback, from upstream to downstream, or from material to product as shown in Fig. 9. Since we recognized that the research itself would not be possible unless the materials and components were not available at the industrial level, the companies in the figure had minimum commercial mass production systems. On the other hand, for core technology, a support system was constructed by a close network of universities and public research institutions to enable thorough and careful technical assistance for potential technologies and technical issues in various aspects as shown in Fig. 10. In this scheme, rather than each business engaging in technological development independently, they were encouraged to be part of integrated technological development that progressed in a planar manner. In the network of core technology, the significance and positioning of the individual technological issues were not left to become isolated, but were made clearly visible, so elemental technology could be developed while maintaining direct relationship with industry. As a secondary result in the core technology network (perhaps this is an ultimate outcome for a public institution), we were able to possess a successful experience of the R\&D method where one scenario was shared and the direction was determined, and a collaborative research platform was created for integrated technological development. Not limited to noncombustible magnesium, this platform is expected to become the center of growth of various innovations.

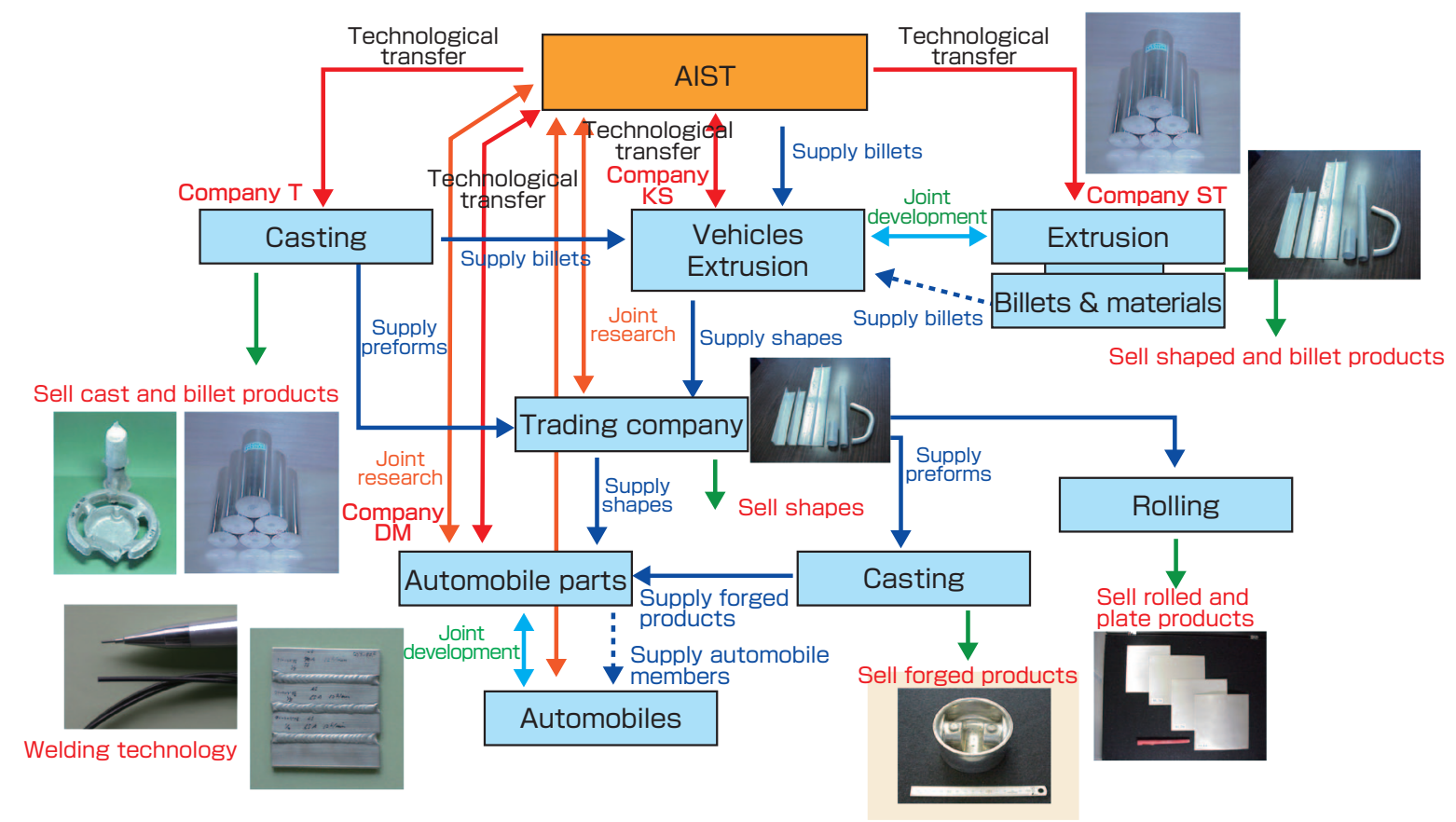

Fig. 9 Mass production system for noncombustible magnesium alloy. 


\section{Current state of practical use and R\&D}

\section{- Casting material and billet for plastic forming}

The materials for plastic forming must be highly clean and have the highest quality possible, and the quality of the material in the most upstream position greatly affects the quality and cost of the plastic formed products. We transferred the molten metal refining technology by reduced pressure method to three material supplier companies, and is engaging in usage development and mass production of high-quality, low-cost billet materials. We selected multiple companies as material manufacturers to ensure stable supply of the material. One company was capable of an integrated mass production system from billet manufacturing to extrusion, while another company was a casting company capable of multi-type low-volume production, and we aimed for a flexible production system considering the future demand for machinery structure components. The photographs on top right and left center in Fig. 9 show the plastic forming billet in rod form.

\section{- Casting material}

Since the noncombustible alloy does not burn readily in the atmosphere, casting is possible at low cost in the casting process where metal is melted and then solidified in a mold. Therefore, we are working on R\&D for casting technology for various machinery components with the aforementioned casting companies. Casting itself can be done in a similar manner as aluminum, and it should be specifically mentioned that green sand casting in the atmosphere is possible in the case of AZ91-based noncombustible alloy. However, since the noncombustible alloy has poor flow property compared to ordinary alloys due to its special solidification structure, and also since solidification occurs rapidly due to its low heat capacity compared to aluminum and casting iron, the problems in casting methods and their conditions are not entirely solved. In actual practice, technology, experience, and know-hows must be accumulated. However, it has definite cost advantage, and application to various machine parts are expected in the future. Figure 11 is an example of the shelf support that was selected for use in the state-of-theart Shinkansen car. It is made of die-cast noncombustible alloy AZX912, and this is the first time in the world for a

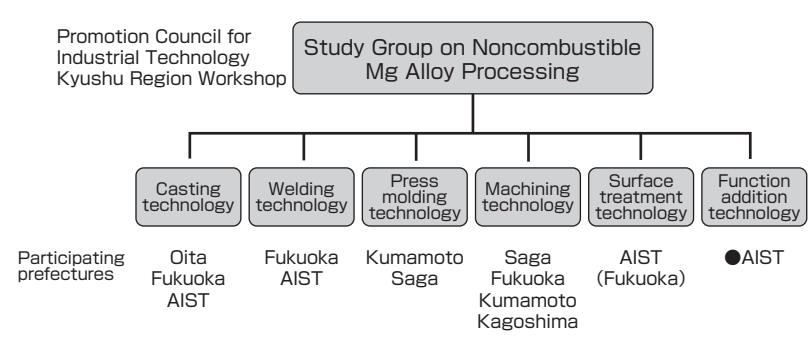

Fig. 10 Core research system for processing technology of noncombustible magnesium alloy by public research institution collaboration. magnesium component to be used in a railroad vehicle.

\section{- Hot extruded shape materials}

Long products with complex but uniform cross section like the aluminum window frame can be mass-produced efficiently, by applying pressure to the metal and pushing it through a perforated die. The extruded materials that are easily formed into shapes with complex cross sections or hollow interiors are basic industrial materials. Since the noncombustible magnesium alloy can be fabricated easily into shapes by the hot extrusion process, usage development is being conducted by the aforementioned billet company and the aluminum extrusion specialist company. Currently, as the first practical application of noncombustible magnesium shape, the specialist company created a product in the form of a square pipe to be used as gate bars for the ETC (Electronic Toll Collection) system at the expressway toll gates. There was a demand for weight reduction, as there were many cases where the shaft of the conventional aluminum bar broke due to the increased frequency of opening and closing of the gate bar. Initially, CFRP was used, but from the perspectives of product price and recycling after exchanging with a new bar, it was changed to the noncombustible magnesium alloy product. It was not merely a replacement of aluminum for further weight reduction, but this was an interesting and illustrative example of a material alternative where high specific strength and recyclability were the key considerations.

\section{- Hot forged material}

Forging is done by beating a simple-shaped metal material to improve strength and reliability. By forging using a mold, parts with uniform quality can be mass-produced, and it is an important processing technology in industry. Forging of noncombustible magnesium alloys is more difficult compared to other alloys, because cracks occur readily unless the temperature and speed of the process are finely controlled. However, in forged materials with fine recrystallized structure by preliminary hot extrusion processing, the forgeability improves dramatically and high speed forming using a hammer forger is possible. Therefore, even if the addition of preliminary extrusion increases the number of steps, there may be advantage in terms of total cost for

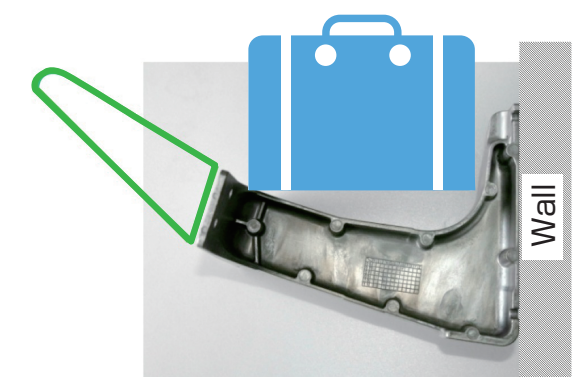

Fig. 11 Luggage shelf support made of noncombustible magnesium alloy (AZX912). 
some products, and joint development is in progress with automobile parts manufacturers. However, the manufacturing cost is a barrier at present, and basic research must be conducted by returning to the basic principles as soon as possible to overcome this issue, as mentioned in section 3.2.

\section{- Plate material}

Metal plates can be easily formed into various shapes, and therefore they are basic industrial materials. Normally, they are formed by rolling the metal at room or high temperature between two rollers to make thin plates. Although magnesium alloy plates are highly in demand, rolling is difficult since the material tends to crack. Therefore, it requires more rolling processes compared to aluminum and other metals, and that increases the price. Although there are limitations on size and precision, the plates can be manufactured satisfactorily by hot extrusion. The aforementioned two extrusion companies have easily manufactured plates with thickness of $1 \mathrm{~mm}$ or less. It is also confirmed that good properties are shown when the extruded material is rolled afterwards. Here, one advantage of noncombustible alloys is that thin sheets can be manufactured since there are no worries of ignition or oxidation at temperature required for hot rolling, and the rolling company has succeeded in manufacturing products with thickness of $0.1 \mathrm{~mm}$. However, the manufacture process of plates requires several steps and therefore, the cost is a more serious problem than forging. For mass supply of low cost plate materials, more technological developments including development of material with good formability are necessary.

\section{-Welded structures using extruded materials}

The structures fabricated by joining plastic formed materials such as forged, plate, or extruded materials are core technologies for various applications to automobiles, railroad vehicles, aircrafts, and other machine structures. Figure 12 is an example of such an application - passenger seats for railroad vehicles. This product cleared the current standard for seats for train cars and is expected to play a role in weight reduction. We presented the product to the Japan Railway Company, and it is under consideration. Even

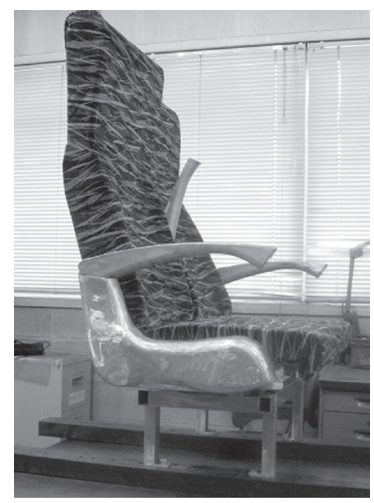

Fig. 12 Railroad vehicle seat made of noncombustible magnesium alloy (AMX602). for just one item such as this seat, integrated technology is important since it involves cast, extruded, and plate materials, as well as bending and pressing processes. Joining requires guarantee of reliability through basic joining and fatigue tests. In this example, TIG welding ${ }^{\text {Term } 5}$ was used, and fabrication of a welding rod for this process was necessary. Also, in some parts, new surface treatment appropriate for noncombustible alloys was done. This shows that a wide range of technological integration is necessary in actual product development, and feedbacks from universities and public research institutes in the aforementioned $R \& D$ network were very important for the investigation of all elemental technologies.

\section{Remaining issues}

To nurture one material as a core material, extremely wide-ranging technological development from upstream to downstream and the accumulation of technologies are necessary. In that sense, rather than asking what are the remaining issues, we must say we just arrived at the starting line of development. However, we must develop the technology to utilize magnesium as an environmentfriendly material for the future. To accomplish this, a wide scope of technological development for the material must be considered from the perspective of life cycle assessment, starting with ore mining, as well as the refining, processing, and recycling technologies, and the social system of cascade recycling. Particularly, the current refining process consumes high quantity of energy as exemplified by titanium and aluminum, and the effort for true energy saving has just begun. Although the potential in Japan for refining technology has advanced remarkably, innovative breakthrough is strongly desired. On the other hand, there are still mountains of issues such as quality assessment technology for molten metal and ingot, low-cost surface treatment technology, highly reliable joining technology, as well as standards for various materials and standardization of the assessment technologies. We hope to solve the above issues, and achieve commercialization of the core materials by employing low environmental load and low cost processes.

\section{Terminology}

Term 1. Smelting: The process of working metal in its molten stage. This includes casting where the molten metal is poured into a mold and then hardened, as well as manufacturing of metal blanks for plastic forming. In contrast to smelting, there are methods where metal powder is hardened and formed, as well as plastic forming where metal is deformed into shapes.

Term 2. Cold process and hot process: Differentiation is made according to the temperature range when plastic forming metals. When metal crystal is plastic formed at low temperature such as room 
temperature, hardness and strength can be increased (work hardening), but the formability decreases due to cracks. When plastic forming is done at high temperature, the formability increases dramatically although strength cannot be improved. In general, the former is called cold processing and the latter is called hot processing. By heating the processed material to a certain temperature, the crystals undergo a phenomenon of recrystallization where new crystal grains are formed without distortion. Strictly speaking, processing at low temperature without recrystallization is cold processing, and processing at high temperature with recrystallization is called hot processing.

Term 3 T4 treatment: One of the heat treatment processes to control the mechanical properties of metals. When an alloy element added to a base metal is maintained at high temperature, dispersed evenly, and then cooled rapidly, the alloy metal that usually precipitates at low temperature can be solidified in a state where it remains dissolved in the base metal, and this is called solution. When the solution material is maintained at an appropriate temperature for some time, the dissolved alloy elements precipitate into the base material as fine crystals, and the properties such as strength, hardness, and ductility change. This series of heat treatment is called aging. Aging done at room temperature from the solution state is called natural aging, and aging forced at high temperature is called artificial aging. Among various heat treatment methods, these two are used frequently in the field of light metals. The former is known as T4 treatment while the latter is T6 treatment.

Term 4 Inclusion initiation point: The reduction in strength due to fatigue is caused by microscopic cracks in an object, and these cracks become gradually larger by repeated applied force. The first microscopic crack occurs in a place where stress is concentrated in the object. Stress concentration occurs in various places, but most often occurs around heterogeneous solid impurities (in metal, nonmetallic inclusions such as oxides). When the bond between the interface of such an inclusion and the base metal is weak, the presence of an inclusion becomes a defect of the base metal, and functions similarly to microscopic cracks. The failure is then initiated around the inclusion.

Term 5 TIG welding: Tungsten inert gas welding. One of the welding methods where the metal is melted and joined using arc discharge. This is a method of joining by melting the base metal by producing an arc from a tungsten rod by applying high voltage between the base metal and the tungsten rod with high melting point. Basically, this is done by hand so it can be applied to complex shapes, and it is widely used for welding non-iron metals.

\section{References}

[1] M. Sakamoto, S. Akiyama, T.Hagio and K. Ohgi: Magnesium e no calcium tenka niyoru sanka himaku tokusei no henka to nannenka (Change of oxide film property by addition of calcium to magnesium and its combustibility), Chuzo Kogaku (Journal of Japan Foundry Engineering), 69, 227-233 (1997) (in Japanese).

[2] Y. Kitahara, K. Ikeda, H. Shimazaki, H. Noguchi, M. Sakamoto and H. Ueno:Nannensei magnesium gokin no hiro kyodo tokusei (AMCa602B no hiro kyodo ni oyobosu hikinzoku kaizai butsu no eikyo (Endurance strength property of noncombustible magnesium alloy (effect of nonmetallic inclusion on endurance strength of AMCa602B)), Fatigue strength characteristics of noncombustible Mg alloy (1 paper: Effect of non-metallic inclusion on fatigue strength of AMCa602B), Kikai Gakkai Ronbunshu (Japan Society of Mechanical Engineers Journal), 57, 7-8 (2004) (in Japanese).

[3] Y. Kitahara, K. Ikeda, H. Shimazaki, H. Noguchi, M. Sakamoto and H. Ueno:Nannensei magnesium no hiro kyodo tokusei (dai 1 po, 3 shurui no nannensei magnesium gokin no teiryoteki hiro kyodo tokusei) Endurance strength property of noncombustible magnesium alloy (First report - quantitative endurance strength property of three types of noncombustible magnesium alloys), Fatigue strength characteristics of non-combustible $\mathrm{Mg}$ alloy (2nd report: Quantitative comparison among fatigue strength of three non-combustible Mg alloys), Kikai Gakkai Ronbunshu A (Japan Society of Mechanical Engineers Journal A), 72, 661668 (2006) (in Japanese).

[4] K. Ikeda, Y. Kitahara, H. Noguchi, M. Sakamoto and H. Ueno: Nannensei magnesium gokin no hiro kyodo tokusei (yokyoku sanka kotingu zai no tokusei) (Endurance strength property of noncombustible magnesium alloy (property of anodized coating material)), Fatigue strength characteristics of non-combustible Mg alloy (3rd report: Fatigue characteristics of the anodized non-combustible Mg alloy), Kikai Gakkai Ronbunshu (Japan Society of Mechanical Engineers Journal), 57, 9-10 (2004) (in Japanese).

[5] F. Noguchi, S. Yoshida, M. Yamane, K. Kakimoto, T. Tachibana, N. Sakamoto and K. Kawata: Magnesium oyobi magnesium gokin no haisui shori eno oyo (Application of magnesium and magnesium alloy to waste water treatment, Shigen Sozai Gakkai Shunki Taikai Gaiyo (Abstracts of the Spring Conference, The Mining and Materials Processing Institute of Japan), (2006) (in Japanese).

[6] F. Noguchi, S. Yoshida, M. Yamane, K. Kakimoto, T. Tachibana, N. Sakamoto and K. Kawata: Haisui chu no yugai kinzoku no jokyo to yuka kinzoku no kaishu - haisui chu no As no jokyo (dai 1 po) (Removal of harmful metals in waste water and recovery of valuable metals - Removal of As in waste water (first report)), Nihon Tekko Kyokai Dai 149 kai Shunki Koen Taikai Gaiyo (Abstracts of the 149th Spring Conference, The Iron and Steel Institute of Japan), (2005) (in Japanese).

[7] F. Noguchi, S. Yoshida, M. Yamane, K. Kakimoto, T. Tachibana, N. Sakamoto and K. Kawata: Haisui chu no yugai kinzoku no jokyo to yuka kinzoku no kaishu - magnesium ni yoru haisui chu no Cr no kaishu (dai 2 ho) (Removal of harmful metals in waste water and recovery of valuable metals - Recovery of Cr in waste water by magnesium (second report)), Nihon Tekko Kyokai Dai 153 kai Shunki Koen Taikai Gaiyo (Abstracts of the 153rd Spring Conference, The Iron and Steel Institute of Japan), (2007) (in Japanese). 


\section{Authors}

\section{Michiru Sakamoto}

Graduated from the School of Sciences, University of Tsukuba in 1980, and completed the doctorate at the Institute of Geosciences, University of Tsukuba in 1985. Doctor (Geology). Joined the Machinery and Metal Section, Kyushu National Industrial Research Institute, Agency of Industrial Science and Technology in April 1985, and worked on R\&D of metal matrix composites. Appointed to the Materials Research Institute for Sustainable Development, AIST in August 2007, and transferred to AIST Chubu in November 2007. In this paper, clarified the non-combustion mechanism of the noncombustible magnesium alloy, and built and managed the collaborative network.

\section{Hidetoshi Ueno}

Graduated from the Fukuoka Prefectural Ukiha Industrial High School in 1965. Joined the Machinery and Metal Section, Kyushu National Industrial Research Institute, Agency of Industrial Science and Technology in April 1965, and worked on the R\&D of metal matrix composites. Became leader of the Environment Adaptable Alloy Development Group, Materials Research Institute for Sustainable Development, AIST in 2001. Worked steadily on lightweight metal materials, and developed a practical processing technology for metal matrix composites and succeeded in the realization of foamed aluminum. In this study, mainly worked on plastic forming process of noncombustible magnesium alloys.

\section{Discussion with Reviewers}

\section{Positioning of magnesium alloys}

\section{Comment \& question (Toshimi Shimizu, Coordinator AIST)}

The social value of this study is energy saving through weight reduction and improved efficiency of transportation machinery and machine components. However, it is unclear why magnesium is the target of research instead of the current core materials of iron, steel, aluminum, and CFRP that are mentioned in the text. In chapter 1, I think you need to clarify the positioning of magnesium as background for introducing the scenario.

\section{Answer (Michiru Sakamoto)}

The goal is to achieve weight reduction of transportation machineries at a different level than with the existing core materials such as iron, steel, and aluminum, by making magnesium noncombustible and establishing its position as a core material. There aren't many materials that have the potential as core materials, and we consider magnesium as one of the few candidates.

Considering the volume of transportation machineries that are the foundation of society, the material for their weight reduction must be a core material that can be supplied readily like iron, steel, and aluminum. Therefore, we selected magnesium from the perspective of a material having such a qualification as an industrial material. Qualitatively, there are many materials that can be considered lightweight. Also, I don't think the existing transportation machinery system will be used in the future, and it is certain that a new system will emerge and the component materials may be totally different from the existing materials. However, considering the use as structural material, stability of supply equivalent to the existing iron, steel, and aluminum is necessary, and an assurance in terms of environmental load is also necessary.

\section{Creation of scenario with product realization in mind}

Comment \& question (Norimitsu Murayama, Advanced Manufacturing Research Institute, AIST)

The point that is interesting from the viewpoint of synthesis is, when the noncombustible property of magnesium by addition of calcium was discovered, which elemental technologies you set for development and how you designed and planned your research toward product realization. Also, I am very interested in research after the refining technology. Did you select the reduced pressure method assuming the effect of the oxide film formed on the molten metal surface? Did you have refining of structure by extrusion, and the subsequent forging and rolling in mind when you initially wrote the scenario? I imagine there were many trials and errors. Isn't the coexistence of trial and error and inevitability a characteristic of a scenario for material development?

\section{Answer (Michiru Sakamoto)}

Researchers like us are not very good at scenarios with product realization in mind, while it is routine for companies, and it is important to set up a scenario that leads to product realization most efficiently and at a shortest route possible. However, even if it is the shortest route, it won't work if the route is "off the wall," and a solid technological backing is important. I think that role can be filled by the collaborative organization of university and public research institutions. Here, for the collaborative organization to share a common scenario is important, and without a scenario, the researches will be scattered and they will be points without linkages.

\section{Energy saving effect by weight reduction of components \\ Comment \& question (Toshimi Shimizu)}

The research progressed under the mission to achieve weight reduction of most moving things, and the main result is the cast material using noncombustible magnesium alloys that was employed as a shelf support in the state-of-the-art Shinkansen. Although I sort of understand the initial idea of weight reduction, I think the readers' understanding will be bettered if you add some quantitative figures showing how much weight reduction or energy saving was accomplished by employing this shelf support. Answer (Michiru Sakamoto)

Your indication that the contribution of weight reduction to energy saving will become clearer if we present actual figures is very true, and we are keenly aware of this point. However, showing the energy saving effect is not so easy. For example, in our joint research with a certain automobile manufacturer, clear difference was measured between a magnesium piston and an ordinary aluminum piston in an engine bench test for a piston of the reciprocating engine. However, this is only a test, and the realization of the piston is still in a development stage. The weight of a Shinkansen is about 50 tons per compartment. The weight of the noncombustible magnesium shelf support is $15 \mathrm{~kg}$. Direct comparison is difficult since this is not a direct replacement of aluminum parts to magnesium and there was a change in design, yet the weight reduction is about $7.5 \mathrm{~kg}$ in total. In the state-ofthe-art Shinkansen car project, the primary goal was weight reduction of $500 \mathrm{~kg}$ per compartment. Although it is only 7.5 $\mathrm{kg}$, there was some contribution, and the vehicle manufacturer was very grateful. It is difficult to see the effect of this weight reduction now, but I think it will eventually become a common material that will be used normally in various components in the future.

4 Industry-academia-government collaboration scheme 


\section{Comment \& question (Norimitsu Murayama)}

I think the key to success of this research is that you were able to create a collaborative organization with a common objective by several companies in different businesses that took interest in the discovery of noncombustible magnesium. Please tell us the points you found difficult or the issues you worked around in creating a collaborative organization, such as in handling intellectual property, making adjustments among companies, and in connecting companies, universities, and public institutions.

Answer (Michiru Sakamoto)

What was important in creating a collaborative organization was first and foremost the matching of philosophy. This means that the members of the collaborative organization are companies that share consciousness that environment friendliness is most important for society and the realization of noncombustible magnesium alloys must be conducted in this framework. Many people, including the authors, tend to think the companies are only interested in technological development and the profit they can make from it, but actually they routinely make decisions taking into consideration the social issues that lie at the base of the technological development. The members of this organization finally boiled down to companies with such consciousness. Here, it was significant that the university played the role of supporting the philosophical background of environmental friendliness. In addition, to maintain the motivation of the collaborative companies, it was important for the public research institution to take the stance that the main player was the company. Thinking on greater terms, I think the effort to maintain a common goal as a collaborative organization is important.

However, in reality, various issues such as division of labor and intellectual property arise one after the other as business sets in. To deal with this, I think we have to share as much information as possible, and patiently deal with issues one at a time by discussing them carefully among the members. It was important to set up a place of opinion exchange for all members of the collaborative organization using every opportunity possible, and to repeatedly check our understanding of the direction and scenario. 